\title{
Izquierda(s). Breve ensayo sobre la gestación de una noción del lenguaje político moderno
}

\author{
Carlos Altamirano
}

Universidad Nacional de Quilmes / CONICET

\section{A la izquierda del Padre}

"Las Izquierdas, hay que admitirlo, tuvieron un mal comienzo", escribe David Caute en la primera página de su libro Las izquierdas europeas desde 1789. "Tanto el Nuevo como el Antiguo testamento consideran a las Derechas como símbolo de la bondad y a las izquierdas como símbolo del mal. 'Y pondrá las ovejas a su derecha, y a los cabritos a su izquierda' (San Mateo, 25, 33). De nuevo: 'Y aun os digo que desde ahora habéis de ver al Hijo del hombre sentado a la diestra de la potencia de Dios...' (San Mateo, 26, 64, y San Marcos, 14, 62)".' La preeminencia simbólica de la derecha sobre la izquierda no se canceló en la edad media cristiana. En las representaciones de la Crucifixión, Cristo suele aparecer flanqueado por dos ladrones, martirizados en la cruz como él. El de la derecha es el "buen ladrón", con "los ojos elevados, llenos de esperanza, la cara ligeramente vuelta hacia el Señor"; mientras que el mal ladrón, a su izquierda, "abatido sobre el instrumento de su suplicio, la cabeza caída por el peso de sus pecados y de su incredulidad". ${ }^{2}$

\footnotetext{
${ }^{1}$ David Caute, Las Izquierdas europeas desde 1789, Madrid, Guadarrama, 1965, p. 9.

2 Jean-Claude Schmitt, "À la droite du Père", en $L a$ droite despuis 1789. Les hommes, les idées, les réseaux, París, Seuil, 1995, p. 40.
}

El valor desigual atribuido a los lados derecho/izquierdo no nació con el universo simbólico judeo-cristiano: la connotación negativa del lado izquierdo era parte de culturas europeas remotas y sobrevivió por siglos en el saber popular. Entre los antiguos griegos y romanos se pensaba de mal augurio que determinadas aves, a las que se consideraba agoreras, se presentaran en su vuelo a la izquierda de quien quería vislumbrar su destino, mientras presagiaba buena suerte si asomaban del lado derecho. Un vestigio de esta creencia se encuentra en unos versos famosos del Cantar de Mio Cid, donde el vuelo de la corneja, que aparece una vez a la derecha y otra vez a la izquierda del héroe y su mesnada, contiene un mensaje sombrío: "A la exida de Bivar hovieron la corneja diestra / y entrando a Burgos hobiéronla siniestra". Del latín procedían las palabras contrapuestas, děxter y sĭněxter-tra. En su Breve diccionario etimológico de la lengua castellana, tras conjeturar sobre el complicado itinerario que habría seguido el vocablo izquierdo/a, Joan Corominas comenta: "El fenómeno del paso de una lengua a otra, que se advierte repetidamente en la historia de esta palabra, se explica por el deseo de cambiar un vocablo que en la conciencia popular tiende a envolver la idea de mal agüero". En fin, digamos que aun en el lenguaje corriente de nuestros días hacer algo 
"por izquierda" es hacerlo con tramoyas, por fuera de lo que es recto. ${ }^{3}$

Sin embargo, contra la ascendencia que propone Caute, como términos del lenguaje político moderno la voces derecha/izquierda no remiten a ese pasado lejano ni a sus remanentes en el habla actual. La genealogía de las dos nociones, a la vez inseparables y antagónicas en los enfrentamientos políticos y en los debates ideológicos del mundo contemporáneo, es más corta, y el significado asociado con cada una de ellas proviene de una historia cuyo comienzo remite a Francia y no va más allá de la Revolución Francesa de 1789, la Gran Revolución. Con el tiempo, la oposición izquierda/ derecha será casi universalmente adoptada en países europeos y americanos. Con esta particularidad: el esquema hallará más arraigo en el idioma político de los países latinos que en el de los anglosajones y germánicos.

La relación entre ambos vocablos ya no será jerárquica, sino horizontal. Como escribía Massimo Cacciari en 1982, las "izquierdas europeas no sufren los complejos de la mano izquierda, ni tienen nostalgia de la mano derecha... sino que siempre se han figurado a sí mismas como rectas [o sea, derechas, CA]. $\mathrm{La}$ izquierda ["sinistra", en italiano, CA], en realidad, no se concibió nunca siniestra [o sea "sinistra", también en italiano, CA], sino como la parte del alineamiento político que porfía por la posición recta". Al igual que la derecha, en suma, también la izquierda se considera expresión de la política (cor)recta.

\section{Los dos lados del parlamento}

De acuerdo con un divulgado relato de origen, el nacimiento de la distinción-oposición entre izquierda y derecha se remonta al

\footnotetext{
${ }^{3}$ Massimo Cacciari, "Sinisteritas", en Il concetto di sinistra, Milán, Bompiani, 1982, p. 7.
}

primer año de la Revolución Francesa. En la Asamblea Constituyente (1879-1791), al tratarse en la sesión del 28 de agosto de 1789 la cuestión que promovían los monárquicos (otorgar al rey el poder de veto absoluto en materia legislativa) con el propósito de poner freno a la revolución y moderar las pretensiones del tercer estado, se produjo el doble alineamiento en la sala. Los partidarios de afirmar la autoridad del rey se sentaron a la derecha del presidente de la asamblea; a la izquierda se alinearon, en cambio, los delegados contrarios a conceder esa facultad al monarca. Entonces habría tenido su acta de nacimiento la polarización que iba a caracterizar la vida política francesa durante gran parte del siglo XIX y a lo largo de la centuria siguiente. ${ }^{4}$ Estudios recientes, más atentos a la frontera móvil de los significados y precavidos de los riesgos del uso anacrónico de nociones que solo aparecerían y tendrían vida más tarde, hallarán que ese relato simplificaba demasiado un proceso más complejo y que la cristalización de la dicotomía derecha/izquierda para indicar dos campos de fuerza en la vida cívica llevó más tiempo. La permanencia del vocabulario, esto es, del esquema dualista y las denominaciones correspondientes, puede disimular discontinuidades en la acepción de esas denominaciones.

Según Marcel Gauchet, en un trabajo que rastrea la emergencia y la trayectoria de la pareja izquierda/derecha en la terminología política francesa, esa distinción no sedimenta antes de 1815. Ella solo se consolida en el

\footnotetext{
${ }^{4}$ En su artículo "Sinistra", Mario Tronti se apoya en una de las fuentes de este relato de origen: la Histoire parlamentaire de la Révolution Française ou Journal des Assamblées nationales depuis 1789 jusqu'en 1815, 18331838, obra de cuarenta volúmenes escrita por el socialista cristiano Philippe Buchez en colaboración con Roux-Lavergne (Mario Tronti, Per la critica del presente, Roma, Ediesse, 2013).
} 
período de la Restauración. ${ }^{5}$ La antinomia, sin embargo, observa Gauchet, se hallaba confinada en el lenguaje parlamentario y se usaba para describir las líneas de división del cuerpo legislativo. En otras palabras, derecha/ izquierda no son sino clasificaciones que evocan una topología parlamentaria y no indican todavía, en el lenguaje público, partidos y, menos aun, identidades en las filas de los votantes. Más aun, al relevar las expresiones de la marcha cambiante de los alineamientos, el historiador francés apunta que no hubo bipartición, sino tripartición: tempranamente había surgido un centro, importante en la articulación de la esfera política, y en el lado izquierdo tempranamente cobró visibilidad la existencia de dos izquierdas, una moderada, otra extrema.

También para Maurice Agulhon la noción de izquierda (como la de derecha) es la abstracción de una dinámica de clasificaciones y reclasificaciones en la nomenclatura política francesa que tiene su punto de partida en 1789. "Derecha e izquierda en el lenguaje político nacieron en tiempos de la Revolución Francesa, en torno de ella y a causa de ella, y se prolongaron primeramente en torno de su herencia y de su recuerdo. Nada es más pura y clásicamente de derecha que la bandera blanca (1814-1830), nada es más puramente de izquierda que la bandera tricolor". ${ }^{6}$ Esa dinámica de antagonismos no remite a significados fijos: derecha e izquierda "no se definen por contenidos de programas sino por constantes de tomas de posición en enfrentamientos variables de programas". ${ }^{7}$ Así, en el marco de sucesivas parejas antagónicas, la izquierda

\footnotetext{
${ }^{5}$ Marcel Gauchet, "La droite et la gauche", en P. Nora (dir.), Les lieux de mémoire, vol. III: Les France, París, Gallimard, 1992.

${ }^{6}$ Maurice Agulhon, "La gauche, l'idée, la mot", introducción a Jean-Jacques Becker y Gilles Candar (dirs.), Histoire des gauches en France, París, La Découverte, 2004, p. 25.

${ }^{7}$ Loc. cit.
}

fue liberal (contra los representantes del Antiguo Régimen), republicana (en oposición a los ensayos y proyectos de los monárquicos, fueran legitimistas, orleanistas o bonapartistas), defensora del voto universal masculino frente a la vigencia del voto censitario -precepto de la izquierda era que sin voto universal no había democracia-. Aunque no se podría asociar esa izquierda parlamentaria con una doctrina o un programa inequívocos, se la puede conectar en cambio con una constelación de principios y temas: la reivindicación del legado de la Revolución de 1789, en particular, de la declaración de los derechos del hombre y el ciudadano; la defensa de la Ilustración contra la ignorancia y la superstición; elevación de la ciencia a intérprete privilegiado de la naturaleza y del mundo social; el progresismo, o sea, el convencimiento de que la historia humana avanzaba hacia formas cada vez mejores de sociedad y de convivencia entre los hombres. Esa marcha podía temporalmente detenerse, incluso retroceder, pero tras un intervalo se reanudaba.

A juicio de Agulhon, si hay algo que varía poco en ese despliegue de cuadros cambiantes es que en su curso ni la derecha ni la izquierda controlan el poder político. En la mayor parte del tiempo el gobierno estuvo en manos del centro, a veces con aliados a la derecha (centro-derecha), a veces con apoyos en la izquierda (centro-izquierda).

\section{Reconfiguraciones}

El significado político del término izquierda no permanecerá inmutable. Pero para comprender los sentidos de que se irá cargando con el tiempo ese vocablo, no basta con prestar atención a sus peripecias en los combates del parlamentarismo francés. Hay que tomar en cuenta también otras mutaciones y otros campos de historicidad que serán igualmente focos de producción de sentido. Junto a la 
fluctuante historia de la noción de izquierda como clasificación política asociada con una topología de asamblea, se desarrollaron en Francia otras dos historias - una social y otra ideológica- que van a enlazarse hasta confluir en un mismo cauce a comienzos del siglo XX. La historia social es la del movimiento obrero, sus luchas, sus organizaciones, su prensa. Ciertamente, esa historia, como la del capitalismo, no estuvo circunscripta a un espacio nacional y en Europa conoció tres escenarios principales: Inglaterra, Francia y Alemania. En Francia el desarrollo del movimiento obrero fue más tardío y lento que el de la clase obrera inglesa no solo porque, como en Alemania, la era de la gran industria no comenzó antes de la segunda mitad del ochocientos, sino también porque las clases laboriosas debieron enfrentar una variada y densa trama de obstáculos jurídicos y políticos que desde 1789 obstruirían la formación de gremios obreros. ${ }^{8}$ La resistencia de los trabajadores recurrió a menudo al agrupamiento en sociedades secretas, entidades en que no era infrecuente que artesanos y asalariados se unieran con estudiantes y conspiradores revolucionarios. En la estela de Babeuf y Buonarotti, estos sobrevirían bajo la guía de Auguste Blanqui. Débil en el primer tercio del siglo XIX, el movimiento de los trabajadores comenzó poco a poco a cobrar presencia en los combates sociales y políticos que se libraron bajo la monarquía constitucional de Luis Felipe. En febrero de 1848 la clase obrera ya formaba en las filas del pueblo de las barricadas, el pueblo que ganará las calles y provocará el fin de la llamada Monarquía de Julio. En la agitada y corta vida de la II República que nació de la revolución de 1848, la idea de una "república social" y la reivindicación de la igualdad van a dividir las fuerzas del heterogéneo campo

8 Véase Édouard Dolleans, Historia del movimiento obrero, vol. I: 1830-1871, Buenos Aires, Eudeba, 1960. republicano: ¿igualdad solo jurídico-política entre los hombres o igualdad social, alcanzada a través de una reorganización de la sociedad o bien a través de una revolución que pusiera fin a la propiedad privada de los medios de producción? Los términos socialismo y comunismo, que designaban la acción y la propaganda de agrupamientos y figuras públicas, ya se habían incorporado para entonces al vocabulario político.

El tratamiento de la cuestión de la desigualdad y la simpatía por los desposeídos, los "proletarios", no nos reenvía únicamente a una dinámica de procesos sociales, económicos y políticos, sino también a una historia ideológica: la de las corrientes de crítica radical de la sociedad presente -por su desorganización y por las injusticas que nacían de la propiedad privada de los medios de producción-. La denuncia del mal social acompañaba la condena del orden existente con proyectos palingenésicos del género humano y visiones de la sociedad futura. El discurso de los credos militantes, con sus maestros y sus discípulos, sus publicaciones y sus clubes y logias secretas, no hizo sino proliferar desde el establecimiento la Monarquía de Julio, en folletos, periódicos, panfletos y libros. Ese verbo crítico fue en sus comienzos parte de una "literatura de doctrina", que acompañó el desenvolvimiento de la literatura romántica en la Francia de las primeras décadas del siglo XIX. En ese tiempo se vería nacer, escribe Paul Bénichou, "en la frontera de las letras y de la especulación filosófico-social, sistemas destinados a interpretar las vicisitudes de la Francia moderna y deducir de ellas fórmulas para el futuro". "Una visión de la historia. Conocemos los nombres de las figuras más destacadas de esta etapa de proyectos y ensayos de regeneración social: Saint Simon,

\footnotetext{
${ }^{9}$ Paul Bénichou, El tiempo de los profetas. Doctrinas de la época romántica, México, FCE, 1984, p. 7.
} 
Fourier, Cabet, Pierre Leroux... El periódico Le Globe, dirigido por Leroux y convertido en órgano de la doctrina sansimoniana, habría sido la hoja que introdujo el vocablo socialisme en la lengua pública francesa. ${ }^{10} \mathrm{El}$ primer significado de esa palabra residía en la oposición al individualismo propio de las doctrinas liberales. Los estudios históricos bautizarán esta etapa primera de doctrinas de reforma o revolución social con diferentes nombres: romanticismo social, socialismo romántico, socialismo utópico, socialismo pre-marxista.

Durante un tiempo, el discurso crítico-utópico contrastaba, en Francia, con un movimiento obrero que hasta la tercera década del siglo XIX era todavía débil. Poco a poco, a medida que ese discurso hallaba eco y adeptos en las agrupaciones, a menudo ilegales, de las clases laboriosas, se producirá el encuentro entre el descontento de los trabajadores y las doctrinas que explicaban las causas del mal social e indicaban los cambios necesarios para terminar con ella. En fin, hay que tomar en cuenta también, en esta dinámica de procesos sociales, los efectos de la implantación del sufragio universal masculino, que será una de las conquistas de la revolución de febrero de 1848. Hasta entonces, la Francia que participaba en la vida cívica, el pays légal, abarcaba solo una fracción minoritaria de la sociedad nacional. La introducción del sufragio universal masculino dilató el país legal a las dimensiones de la nación. ${ }^{11}$ Los efectos de este cambio no serán inmediatos: pese a la vigencia del voto universal, hasta el último cuarto del siglo XIX la política seguirá siendo

\footnotetext{
${ }^{10}$ Véase Armelle Le Bras-Chopard, "Les premiers socialistes", en Pascal Ory (dir.), Nouvelle Histoire des Idées Politiques, París, Hachette, 1987; también George Lichtheim, Los orígenes del socialismo, Barcelona, Anagrama, 1970, p. 59.

${ }^{11}$ René Remond, Les droites en France, París, Aubier, 1982, p. 100.
}

asunto de notables, que dirigían comités electorales efímeros y que contaban con el apoyo de algún diario.

De acuerdo con la perspectiva de George Lichtheim, la Revolución Francesa de 1848 obró doblemente: constituyó, por un lado, una "gran frontera" histórica -en adelante ya no podría describirse el desarrollo de las ideas socialistas sin dar cuenta del movimiento obrero-; por otro lado, fue solo una etapa "en el camino que llevó a 1871 y a la Comuna de París". En el intermedio de esas dos fechas, escribe, "Francia perdió la primacía dentro del movimiento socialista, al igual que el liderazgo político de Europa occidental. El cambio se simboliza en el sistema intelectual que lleva el nombre de Marx: una síntesis de teorías alemanas, francesas e inglesas surgidas durante la era anterior, la era que finaliza en $1848 " .{ }^{12}$

La referencia a Karl Marx y a la gravitación de su obra me lleva a hacer un breve comentario. No podría afirmar que el autor de El Capital nunca haya hecho uso de la distinción derecha/izquierda en sus análisis, pero sí que tal oposición no formó parte de su caja de herramientas, de su lenguaje teórico-político. Si la empleó, fue muy raramente. Es difícil suponer que desconociera ese esquema dualista. Había vivido en París entre 1843 y 1845 y durante su permanencia en la capital francesa, que por entonces era el foco de la agitación revolucionaria de Europa, se había familiarizado con la literatura socialista y comunista. En el prólogo a la tercera edición de El Dieciocho Brumario de Luis Bonaparte, Friedrich Engels destacaba el gran conocimiento que tenía Marx de la historia de Francia. En ese país más que en ningún otro, observaba Engels, "las luchas históricas de clase" se habían desarrollado hasta su punto decisivo. Había ocurrido con la Gran Revolu-

${ }^{12}$ Ibid., p. 66. 
ción, que liquidó el feudalismo para dar paso a la "dominación pura de la burguesía"; y así ocurría en el presente con la lucha del proletariado revolucionario contra la burguesía. Por eso, continuaba, "Marx no solo estudiaba con especial predilección la historia pasada de Francia, sino que seguía también en todos sus detalles la historia contemporánea, reuniendo los materiales para emplearlos ulteriormente, razón por la cual nunca le sorprendían los acontecimientos". ${ }^{13}$ Ahora bien, ni en $\mathrm{La}$ lucha de clases en Francia de 1848 a 1850 (1850), ni en El Dieciocho Brumario (1852), es decir, en ninguno de los dos escritos que Marx dedicó a analizar los enfrentamientos sociales y políticos del crucial período que iba de la caída de Luis Felipe (24 de febrero de 1848) al golpe de Estado de Luis Napoleón Bonaparte ( 2 de diciembre de 1851) se encontrará el uso de la antítesis derecha/izquierda o alguno de sus dos vocablos para describir o interpretar tendencias o actores históricos. $\mathrm{Si}$ es improbable que desconociera ese esquema, más bien cabe pensar que la distinción derecha/izquierda estuviera demasiado identificada con el juego político parlamentario y que Marx no la juzgara relevante para los conflictos que se proponía narrar y explicar -los conflictos de clase que juzgaba sustantivos desde el punto de vista del materialismo histórico-. También en el Manifiesto del Partido Comunista (1848) el clivage derecha/izquierda se halla ausente. Recordemos el comienzo de ese célebre texto: el "fantasma" que recorre Europa y contra el cual se arrojan todas las fuerzas reaccionarias del viejo mundo no es el fantasma de la izquierda, sino el del comunismo. El fantasma no era tricolor, sino rojo.

\footnotetext{
13 "Prólogo de F. Engels a la tercera edición alemana", en Carlos Marx, El Dieciocho Brumario de Luis Bonaparte, Buenos Aires, Editorial Polémica, 1972, p. 13.
}

\section{Las familias de izquierda}

Para el período que media entre 1815 y 1870 , observa Maurice Agulhon, el empleo de los vocablos derecha e izquierda no refleja el lenguaje de la época sino que tiene carácter retroactivo. Las dos palabras hacían todavía referencia a las divisiones dentro del recinto parlamentario. "Los hombres que luchaban por la democracia en los años ' 60 se pensaban y se decían pertenecientes al partido de la libertad, de la república o bien de la Revolución, más bien que de la izquierda." ¿Y los obreros? Los más activos y más conscientes de que los intereses del trabajador no eran los del patrón -el proudhoniano Henry Louis Tolain, que será una figura importante en la creación de la 1ra. Internacional, podría ser un ejemplo--, ${ }^{14}$ se reconocerán como socialistas antes que como partes de la izquierda. Fue sobre todo tras el fin del Segundo Imperio, ya en los años de la llamada Tercera República, "cuando las luchas en el país y los partidos parlamentarios se han relacionado de manera estrecha y duradera, cuando -también- la república que ha llegado al poder pudo ser objeto de adhesiones diversas e interpretaciones rivales, que las palabras derecha e izquierda cobraron generalidad y coherencia". ${ }^{15}$

En el último cuarto del siglo XIX se reactivará el clivage derecha/izquierda, pero ahora la antítesis ya no remite solo a alineamientos parlamentarios sino también a corrientes de opinión radicadas en la sociedad francesa. Por lo que se refiere a la izquierda, no se podría hablar de partidos, si con este término se piensan organizaciones estructuradas y permanentes. Hasta comienzos de la década de

${ }^{14}$ Dolleans, Historia del movimiento obrero, vol. I, pp. 240-248.

${ }^{15}$ Maurice Agulhon, "La droite et la gauche: lutte de classes ou luttes d'idées", en id, Histoire vagabonde. II: Idéologies e politique dans la France du XIX siècle, París, Gallimard, 1988, p. 217. 
1890 lo que se denominaba "partido socialista" constituía un variado conjunto de "partidos", grupos, comités y periódicos, una miscelánea trabajada por muchas escisiones. ${ }^{16}$ No era diferente la configuración de los radicales, la otra corriente que se identificaba como parte de la familia de izquierda -una familia que no era revolucionaria, sino inclinada a seguir el camino de las reformas sociales y políticas-. La república estaba en el corazón de esa izquierda. De hecho, será el propósito de salvaguardar la república, a la que veían en peligro por la acción y la propaganda cada vez más beligerante de una derecha nacionalista y clerical, lo que impulsará la formación del Bloc des gauches en 1899, una coalición que unirá a socialistas, radicales y radicales-socialistas con la moderada Alliance Democratique, de Pierre Waldeck-Rousseau, que encabezaba el gobierno. ${ }^{17}$

Los alineamientos en la escena política prolongaban la división que el caso Dreyfus había hecho emerger y cristalizar en la sociedad y la opinión pública franceses. El bloque de la izquierda reformista enfrentó y batió en las elecciones legislativas de 1902 a la "otra" Francia, de ardor también militante, animada por el chovinismo y el antisemitismo, la defensa del honor del ejército, la apología del catolicismo. Al igual que la Revolución de 1789 y la Comuna de 1871, indica Vincent Duclert, el affaire fue un jalón de la historia de la izquierda en Francia: "Los desgarramientos de los partidos anarquistas, socialistas y radicales, el coraje de algunos líderes

${ }^{16}$ Gilles Candar, "Jaurès et le parti, retour sur un itinéraire”, Cahiers Jaurès, 2008/1 (№ 187-188), pp. 15-27. URL: <https://www.cairn.info/revue-cahiers-jaures-20081-page-15.htm $>$.

17 Antonio Robles Egea, "Las coaliciones de izquierdas en Francia y España (1899-1939)", Cahiers de civilisation espagnole contemporaine, puesta en línea el 2 de marzo de 2015, consultado el 29 de marzo de 2019 URL: <http://journals.openedition.org/ccec/5404; DOI: $10.4000 /$ ccec.5404>. políticos y parlamentarios, la fuerza de las vanguardias intelectuales y culturales, el reconocimiento de lo que se jugaba en términos de humanidad y justicia en el combate por Dreyfus, la primera participación de un socialista en un gobierno 'burgués', el de la 'defensa republicana' de Waldeck-Rousseau, transforman el Affaire en un acontecimiento fundador de una nueva era de la izquierda". ${ }^{18}$

La coalición, que duró hasta 1906, llevó al socialista Alexandre Millerand a integrar el gobierno como ministro de industria. La participación del político socialista en un gobierno burgués (el "millerandismo", como se denominará esta actitud) dará lugar a un gran debate en las filas de los partidos socialistas reunidos a partir de 1889 en lo que se conocerá como Segunda Internacional. Desde la última década del siglo XIX los partidos socialistas se habían multiplicado a lo largo del mundo y el marxismo era ya la doctrina preponderante en el seno de estas organizaciones que representaban, o buscaban representar, los intereses de los trabajadores en las luchas sociales y políticas. ${ }^{19}$ Karl Kautsky, figura central del partido social-demócrata alemán que va a dar forma a la primera versión de una ortodoxia marxista, intervino en la polémica que suscitó la cuestión Millerand. Kautsky objetará el comportamiento del socialista francés. Sostenía que la colaboración del par-

\footnotetext{
${ }^{18}$ Vincent Duclert, "L' affaire Dreyfus et la gauche", en Jean-Jacques Becker y Gilles Candar (dirs.), His toire des gauches en France, París, La Découverte, 2004, p. 200.

19 "En el período de pasaje de la I a la II Internacional, la teoría de Marx se vuelve un factor esencial en la polifonía ideológica. El interés por los escritos de Marx y de Engels se acrecienta y su difusión se expande. Todas las tendencias y todas las corrientes del pensamiento socialista de ahí en adelante en relación con las posiciones teóricas de los fundadores del "socialismo científico." George Haupt, "Marx e il marxismo", en Storia del marxismo, vol. I: Il marxismo aitempi di Marx, Turín, 1978, p. 302. La excepción eran los anarquistas, que terminarían expulsados de la Internacional.
} 
tido obrero con un gobierno burgués se justificaba excepcionalmente -cuando la reacción amenazaba la existencia de la república-, pero aun entonces había que mantener el principio de la lucha de clases y salvaguardar la independencia política y organizativa del partido. El gradualismo y el reformismo debían rechazarse. Para Kautsky la instauración del socialismo exigía una ruptura con el conjunto del ordenamiento burgués. ${ }^{20}$

A lo largo del siglo xx el "pueblo de izquierda" conocerá nuevos integrantes y nuevos debates y realineamientos al ritmo de las pruebas y los desafíos que procedían de la historia: la Gran Guerra, la Revolución Rusa, el surgimiento y la expansión del fascismo, el estalinismo, las revoluciones anticoloniales, el conflicto chino-soviético. Comunistas, trotskistas, cristianos de izquierda, neo-izquierdistas, maoístas, guevaristas, etc., ingresarán en diferentes momentos en ese espacio rotulado de izquierda, muchas veces produciendo reclasificaciones en su interior. En fin, me parece evidente que ya estamos hablando un lenguaje que nos es temporalmente próximo, familiar.

\section{Ecos argentinos}

El esquema de derecha/izquierda dio la vuelta al mundo y, en algún momento, se incorporó también al vocabulario ideológico y político de la Argentina. No podría señalar con certeza cuándo comienza su uso en nuestro país, aunque presumo que debe de haber sido ya en el curso del siglo Xx. Al rastrear rápidamente ese comienzo encuentro dos clases de evidencia: las que testimonian el empleo explícito de las categorías de derecha e izquierda por contemporáneos (o sea, no como categorías

\footnotetext{
${ }^{20}$ Massimo L. Salvadori, "Kautsky fra ortodossia e revisionismo", en Storia del marxismo, vol. II: Il marxismo en l'età della Seconda Internazionale, Turín, Einaudi, 1979.
}

del historiador) y otras que podríamos considerar señas o vislumbres de otra cronología y de una estela un poco más larga. La primera clase de evidencias nos hacen pensar que desde fines de la segunda década del siglo $\mathrm{xx}$ el esquema para clasificar posiciones nacido en Francia se hallaba ya en circulación entre nosotros. En diciembre de 1920, en el congreso del Partido Socialista donde se contraponían puntos de vista diferentes respecto de la posición que debía adoptarse frente a la Revolución Rusa y la Tercera Internacional, Juan B. Justo prevenía contra el empleo inapropiado que se estaba haciendo de aquella antinomia en las filas de la organización. "Las expresiones de izquierda y derecha que se mencionan dentro del Partido, decía Justo, pueden justificarse cuando se trata de definir en una asamblea donde hay representados intereses e ideas, pero no se explican en un Partido en el cual se entra porque se quiere, habiendo propósitos comunes y obedeciendo a normas de conducta que han sido instituidas con la aprobación de la mayoría."21 Resulta imposible no asociar el uso de las clasificaciones que Justo censura con los debates y las divisiones que la Primera Guerra Mundial y la Revolución Rusa produjeron dentro del socialismo, con la adopción del esquema izquierda/ derecha por parte de quienes apoyaban la experiencia soviética.

Otros datos que se registran también en los años veinte confirman que la dicotomía había sido adoptada en el vocabulario público. En 1924 aparece una revista de existencia efímera, Extrema izquierda, de la que verán la luz apenas tres números. Se trataba de una publicación predominantemente literaria, puesta en circulación por escritores del grupo de Boedo (entre otros, colaboraban en ella Leónidas Barletta, Elías Castelnuovo, Ro-

\footnotetext{
${ }^{21}$ Citado en Dardo Cúneo, Juan B. Justo y las luchas sociales en la Argentina, Buenos Aires, Solar, 1997, p. 404.
} 
berto Mariani, Álvaro Yunque). El nombre que le dieron sus editores hace pensar que se situaban a la izquierda de otra izquierda, una izquierda no revolucionaria o moderada. Dos años después se funda la revista Claridad, bajo la dirección de Antonio Zamora, en la que se puede reconocer, desde su título, el modelo de la revista francesa Clarté (19211928), heredera de un movimiento que había pasado del pacifismo al apoyo de la revolución bolchevique. De la revista que editaba Zamora en la Argentina también participaban escritores del grupo de Boedo, pero en Claridad la literatura de ideas tenía el lugar más saliente. Como se leía en su primer número, "Claridad quiere ser una revista en cuyas páginas se reflejen las inquietudes del pensamiento izquierdista en todas sus manifestaciones. Deseamos estar más cerca de las luchas sociales que de las manifestaciones puramente literarias". ${ }^{22}$

Se puede concluir a partir de estas pocas referencias que la oposición derecha/izquierda tuvo su primera carta de ciudadanía dentro de una franja restringida compuesta por políticos, gente de letras, artistas e intelectualesideólogos identificados con la idea de un cambio social radical, simpatizantes de la Revolución Rusa, próximos a o enrolados en el comunismo o el socialismo. Pero hay una discusión parlamentaria, sin embargo, que hace entrever una historia más larga y una cronología diferente del establecimiento de ese $\mathrm{cli}$ vaje en la nomenclatura política argentina. Se ocuparon de ese debate Alberto Ciria (Política y cultura popular, 1983) y después Diana Quattrocchi-Woisson (Los males de la memoria, 1995).

La discrepancia tuvo lugar en la cámara de diputados el 28 de junio de 1946, en oportunidad de la distribución de las bancas, dado que

22 "Apuntes y comentarios", en Claridad, año 1, $\mathrm{n}^{\circ} 1$, julio de 1926. los peronistas habían ocupado los escaños de la izquierda. No somos un partido de derecha, sostendrá en la ocasión el vocero del partido radical, Nerio Rojas. Y, más adelante: "Existen parlamentos como el inglés, donde la distribución de las bancas no tiene significación ideológica; en cambio hay otros, como el francés, donde ello implica una definición. La tradición argentina, a partir del año 1912, tiene en esto una significación doctrinaria como la tiene el parlamento francés". Por eso, agregaba, "no estamos dispuestos a aceptar en silencio que el sector oficialista se proclame de izquierda y que nosotros seamos la derecha". ${ }^{23}$ Varios diputados peronistas, entre ellos John William Cooke, respondieron al discurso de Nerio Rojas, afirmando los títulos de la nueva fuerza para asumir el lugar de la izquierda en el recinto parlamentario. Pero más pertinente para nuestro tema es el argumento que expuso el presidente de la cámara, Ricardo Guardo, para resolver el diferendo. Cito el resumen que hace Alberto Ciria del dictamen Guardo: "Al no existir disposiciones reglamentarias al respecto, Guardo invoca la costumbre para la ubicación de los partidos a derecha o izquierda del recinto, teniendo en cuenta 'la ideología de los programas o plataformas de partido, con prescindencia de que éstos sean partidarios o contrarios del gobierno'. Así ocurrió con los conservadores, que cedieron en 1912 las bancas de la izquierda a los diputados de la UCR, elegidos gracias a la ley Sáenz Peña. Estos, a su vez, hicieron lo propio con los socialistas a medida que obtuvieron bancas en Diputados, con lo cual se demuestra que el sector de la izquierda corresponde a los voceros 'de los partidos de programa más avanzado'. Tanto en el gobierno como en la oposición, radica-

${ }^{23}$ Citado por Diana Quattrocchi-Woisson, Los males de la memoria. Historia y política en la Argentina, Buenos Aires, Emecé, 1995, p. 230. 
les como conservadores continuaron ocupando sus lugares habituales. En consecuencia, la resolución de Presidencia establece que 'la nueva y avanzada tendencia social' del oficialismo, fundamentada 'en una doctrina social de espíritu cristiano', justifica que sus integrantes ocupen el sector izquierdo, y no hace lugar a argumentos de presuntos derechos adquiridos por parte de la UCR". ${ }^{24}$

Otro dato: en el diario de sesiones de la cámara de diputados que surgió de las elecciones de abril de 1912 no hallé ningún registro del nacimiento de esa costumbre o tradición. Pero veamos lo que se podía leer el 28 de mayo de 1918 en el diario La Capital, de la ciudad de Rosario, a propósito de la abrumadora victoria que el radicalismo había obtenido a escala nacional en las elecciones legislativas de 1917: "El comicio ha llevado a las bancas una legión de elementos nuevos poco avezados a la lid parlamentaria... Con estos aportes el fiel de la mayoría, inmovilizado durante tantos años en la derecha, empieza a apuntar hacia la izquierda. Numéricamente el radicalismo es ya dueño de la cámara". ${ }^{25}$

Estas líneas no solo atestiguan el uso de la oposición entre derecha e izquierda según el modelo francés, sino también la clasificación del radicalismo dentro de la categoría de la izquierda. No sabemos cuán extendido estaba ese uso, pero tal vez una exploración más amplia que la ojeada expuesta aquí pueda responder a esa cuestión.

\section{Bibliografía citada}

Agulhon, Maurice, "La gauche, l'idée, la mot”, introducción a Jean-Jacques Becker y Gilles Candar (dirs.), Histoire des gauches en France, París, La Découverte, 2004.

\footnotetext{
${ }^{24}$ Alberto Ciria, Política y cultura popular. La Argentina peronista 1946-1955, Buenos Aires, Ediciones de la Flor, 1893, p. 91.

${ }^{25}$ La Capital, 18/5/1918. Debo esta referencia a la generosidad de la historiadora Virginia Persello.
}

__ "La droite et la gauche: lutte de classes ou luttes d'idées", en Histoire vagabonde II. Idéologies e politique dans la France du XIX siècle, París, Gallimard, 1988.

Bénichou, Paul, El tiempo de los profetas. Doctrinas de la época romántica, México, FCE, 1984.

Cacciari, Massimo, "Sinisteritas", en Il concetto di sinistra, Milán, Bompiani, 1982.

Candar, Gilles, "Jaurès et le parti, retour sur un itinéraire", en Cahiers Jaurès, 2008/1 ( ${ }^{\circ}$ 187-188), pp. 15-27, URL: $<$ https://www.cairn.info/revue-cahiers-jaures-20081-page-15.htm $>$.

Caute, David, Las Izquierdas europeas desde 1789, Madrid, Guadarrama, 1965.

Ciria, Alberto, Política y cultura popular. La Argentina peronista 1946-1955, Buenos Aires, Ediciones de la Flor, 1983.

Cúneo, Dardo, Juan B. Justo y las luchas sociales en la Argentina, Buenos Aires, Solar, 1997.

Dolleans, Édouard, Historia del movimiento obrero, vol. I: 1830-1871, Buenos Aires, Eudeba, 1960.

Duclert, Vincent, "L'affaire Dreyfus et la gauche", en Jean-Jacques Becker y Gilles Candar (dirs.), Histoire des gauches en France, París, La Découverte, 2004.

Engels, Federico, "Prólogo de F. Engels a la tercera edición alemana”, en Carlos Marx, El Dieciocho Brumario de Luis Bonaparte, Buenos Aires, Editorial Polémica, 1972.

Gauchet, Marcel, "La droite et la gauche", en P. Nora (dir.), Les lieux de mémoire, vol. III: Les France, París, Gallimard, 1992.

Haupt, George, "Marx e il marxismo", en Storia del marxismo, vol. I: Il marxismo ai tempi di Marx, Turín, 1978.

Le Bras-Chopard, Armelle, "Les premiers socialistes", en Pascal Ory (dir.), Nouvelle Histoire des Idées Politiques, París, Hachette, 1987.

Lichtheim, George, Los orígenes del socialismo, Barcelona, Anagrama, 1970.

Quattrocchi-Woisson, Diana, Los males de la memoria. Historia y política en la Argentina, Buenos Aires, Emecé, 1995.

Remond, René, Les droites en France, París, Aubier, 1982.

Robles Egea, Antonio, "Las coaliciones de izquierdas en Francia y España (1899-1939)", en Cahiers de civilisation espagnole contemporaine, puesta en línea el 2 de marzo de 2015, consultado el 29 de marzo de 2019. 
URL: <http://journals.openedition.org/ccec/5404; DOI: 10.4000/ccec.5404.>

Salvadori, Massimo L., "Kautsky fra ortodossia e revisionismo", en Storia del marxismo, vol. II: Il marxismo en l'età della Seconda Internazionale, Turín, Einaudi, 1979.

\section{Resumen/Abstract}

Izquierda(s). Breve ensayo sobre la gestación de una noción del lenguaje político moderno

El objeto de este ensayo es esbozar una genealogía del término izquierda en el marco de la polarización derecha/izquierda en el debate público contemporáneo. El vocablo izquierda, como el de derecha, fue en su comienzo y durante parte del siglo XIX solo un término del lenguaje político parlamentario: ambos distinguían posiciones en el espacio restringido de la asamblea legislativa. El surgimiento del término remite a Francia y a una historia que no va más allá de la revolución de 1789. El trabajo destaca las inflexiones de sentido que fue asumiendo el término en la vida política francesa a lo largo de un itinerario que llega hasta el siglo xx. En ese trayecto adquiriría los significados con que se lo conoce en la actualidad. El ensayo se apoya en la investigación de las últimas décadas sobre el esquema derecha/izquierda y en la lectura de léxicos del XIX.

Palabras clave: Republicanismo - Cuestión social - Trabajadores - Socialismo
Schmitt, Jean-Claude, "À la droite du Père", en La droite depuis 1789. Les hommes, les idées, les réseaux, $\mathrm{Pa}-$ rís, Seuil, 1995.

Tronti, Mario, "Sinistra", Per la critica del presente, Roma, Ediesse, 2013.

\section{Left (s). Brief essay on the history of the elabora- tion of a political modern language notion}

The purpose of this essay is to sketch a genealogy of the term left, within the framework of right/left polarization in contemporary public debate. The word left, like that of the right, was at its beginning and during part of the 19th century only a term of parliamentary political language: both distinguished positions in the restricted space of the legislative assembly. The term emergence refers to France and a history that does not go beyond the revolution of 1789. The work highlights the inflections of meaning that the term was assuming in French political life along an itinerary that reaches until the 20th century. In that journey it would acquire the meanings with which it is known today. The essay is based on the research of the last decades on the left / right schema and on the lexicon readings of the XIX.

Keywords: Republicanism - Social question Workers - Socialism 